\title{
AMALAN BERSEDEKAH DALAM KALANGAN GURU PENDIDIKAN ISLAM PRASEKOLAH (The Practice of Act of Giving Among The Preschool Islamic Education Teachers)
}

\author{
Sofiah Mohamed, ${ }^{a}$ Kamarul Azmi Jasmi (PhD), ${ }^{b}$ Nor Azlina Kosnin (PhD), ${ }^{c}$ Nazirah Hamdan, ${ }^{d}$ \\ Mohd Nasri Abdullah, \\ Fakulti Tamadun Islam, Universiti Teknologi Malaysia ${ }^{a, b, d, e}$ \\ Fakulti Pendidikan, Universiti Teknologi Malaysia ${ }^{c}$ \\ *Corresponding author: Sofiah9@live.utm.my
}

\begin{abstract}
Abstrak
Tujuan kajian ini meneroka amalan bersedekah guru dalam pengajaran dan pembelajaran (PdP) Pendidikan Islam prasekolah. Prasekolah merupakan tahap awal kanak-kanak di Malaysia mengikuti kurikulum yang disediakan oleh Kementerian Pendidikan Malaysia (KPM). Pendidikan ini merupakan asas utama dalam usaha mendidik generasi muda pewaris bangsa agar mempunyai ilmu pengetahuan, berakhlak mulia serta mempunyai jati diri yang kukuh. Seramai empat orang peserta kajian dipilih berdasarkan kriteria yang ditetapkan, iaitu mengajar mata pelajaran Pendidikan Islam Kurikulum Standard Prasekolah Kebangsaan (KSPK), mengikuti kursus yang dianjurkan oleh KPM, berpengalaman mengajar mata pelajaran Pendidikan Islam Prasekolah melebihi tiga tahun, dan bersedia serta bersetuju secara sukarela untuk diperhatikan, ditemu bual, dan dianalisis dokumen yang berkaitan. Data bagi kajian kualitatif ini dikumpulkan melalui teknik triangulasi antara data pemerhatian, temu bual, dan analisis dokumen. Data yang dikumpul seterusnya dianalisis menggunakan perisian Nvivo versi 11. Dapatan kajian menunjukkan bahawa berlaku pelbagai penerapan nilai murni dalam PdP Pendidikan Islam Prasekolah. Guru juga menerapkan elemen ini melalui pelbagai cara. Guru menjadikan amalan pemberian hadiah kepada murid sebagai salah satu penerapan amalan murni serta teknik meningkatkan motivasi belajar. Kajian ini menghasilkan satu Model Amalan Bersedekah Guru Prasekolah yang diharapkan boleh memberi panduan dan manfaat kepada ibu bapa, guru, penggubal kurikulum khususnya kepada semua pihak yang terlibat dengan pendidikan awal kanak-kanak. Dapatan ini juga diharapkan memberi impak positif bagi melahirkan generasi yang hebat bermula dari prasekolah sehingga ke pengajian tinggi.
\end{abstract}

Kata Kunci: Bersedekah, Guru Prasekolah, prasekolah

\section{Abstract}

The purpose of this study is to explore the practice of giving teachers in teaching and learning (PdP) Islamic education preschool. Preschool is the level of early childhood in Malaysia following the curriculum provided by the Ministry of education (MOE). These are the primary education in an effort to educate the younger generation successor race so as to have the knowledge, moral and have a strong resilience. A total of four study participants are selected based on criteria, which taught Islamic Education Curriculum Standard National preschool (KSPK), attend courses organised by KPM, teaching the subjects of Islamic Education Preschool for more than three years, and be prepared and agreed on a voluntary basis for observed, interviewed, and analysed documents. Data for the qualitative study collected through triangulasi between the techniques of observation data, interviews, and analysis of documents. The data collected was subsequently analyzed using Nvivo software version 11. The findings show that occur multiple application of moral values in the PdP Islamic education Preschool. Teachers also adopt these elements through a variety of ways. The teacher makes the practice of gift giving to pupils as one applications of charity as well as techniques improve motivation to learn. This study resulted 'Preschool Teacher in Charity Practices Model' that can provide guidance and expected benefits to parents, teachers, curriculum makers especially to all parties involved with early childhood education. This finding also expected a positive impact to produce the next generation of great starting from pre-school to higher education.

Keywords: Charity, preschool teacher, preschool 


\subsection{PENDAHULUAN}

Pendidikan Prasekolah diperuntukkan melalui Akta Pendidikan 1996 di bawah sistem pendidikan kebangsaan. Oleh itu, pihak KPM mengambil tanggungjawab dalam usaha melaksanakan pembangunan pendidikan prasekolah di negara ini. Antara aspek penting yang diperuntukkan oleh Akta Pendidikan 1996, ialah penubuhannya, penubuhan dan penyelenggaraan tadika di bawah kuasa menteri, kurikulum prasekolah, bahasa pengantar, pengajaran Agama Islam dan sebagainya (Sektor Pengurusan Prasekolah, t.t.).

Namun, pelbagai agensi turut menubuhkan prasekolah sama ada dari pihak kerajaan mahupun swasta. Prasekolah kerajaan yang terletak di sekolah rendah adalah di bawah pengurusan Kementerian Pendidikan Malaysia (KPM), Tabika KEMAS (Jabatan Kemajuan Masyarakat [JKM]) yang diurus tadbir oleh Kementerian Kemajuan Luar bandar dan Wilayah (KKLW) serta Tabika Perpaduan (Taman Bimbingan Kanak-kanak [TABIKA]) di bawah kelolaan Jabatan Perpaduan Negara dan Integrasi Nasional (JPNIN), Jabatan Perdana Menteri (JPM). Selain itu terdapat prasekolah di bawah kelolaan kerajaan negeri. Begitu juga terdapat prasekolah di bawah kelolaan pihak swasta telah diwujudkan.

Pihak KPM menetapkan prinsip asas dasar prasekolah. Antaranya adalah dengan menyediakan kemudahan pendidikan prasekolah bagi kanak-kanak yang berumur antara empat hingga enam tahun. Seterusnya, semua prasekolah hendaklah menggunakan Kurikulum Standard Prasekolah Kebangsaan (KSPK). Oleh itu, guru prasekolah perlu mempunyai latihan yang khusus dalam bidang pendidikan prasekolah. Setiap prasekolah perlu mempunyai kemudahan fizikal dan peralatan bersesuaian dan berkualiti. Justeru, semua institusi pendidikan prasekolah perlu mematuhi segala Peraturan Pendidikan Prasekolah 1996 seperti yang diperuntukkan dalam Seksyen 24, Akta Pendidikan 1996. Pihak KPM membuat penyeliaan dari semasa ke semasa bagi memastikan prinsip tersebut dipatuhi (Sektor Pengurusan Prasekolah, t.t.).

Antara objektif KSPK adalah, mengamalkan nilai Islam dalam kehidupan seharian untuk murid beragama Islam (KPM, 2016). Guru sebagai pendidik perlu menerapkan nilai Islam khususnya dalam PdP. Antara nilai Islam yang diterapkan ialah bersedekah. Hal ini kerana, murid prasekolah lebih mudah memahami perkara abstrak jika disertakan dengan praktikal. Oleh itu, menjadi keperluan kepada guru untuk menunjukkan cara bersedekah kepada murid selain memberitahu kepada mereka secara teori.

\subsection{PENGAJARAN DAN PEMBELAJARAN PENDIDIKAN ISLAM PRASEKOLAH}

Proses pengajaran dan pembelajaran (PdP) yang berkesan bergantung kepada guru. Perkembangan murid banyak dipengaruhi oleh suasana di bilik darjah (Mariani Md Nor, 2006). Pengajaran berkualiti menghasilkan pembelajaran yang efektif (Abdullah Ishak, 1995; Noor Hisham Md Nawi, 2011). Melalui tingkahlaku guru, murid belajar sesuatu, iaitu bukan sahaja secara lisan (verbal) malahan tingkahlaku (non-verbal) seperti memberi salam dan senyum dianggap sebagai tingkahlaku guru. Tingkahlaku non-verbal ini ada ketikanya lebih berkesan daripada pengajaran secara lisan khususnya pengajaran nilai dan sikap seperti mana Rasulullah SAW menyuruh sahabatnya solat sebagaimana yang baginda lakukan. Hal ini bermaksud tingkahlaku non-verbal mempunyai peranan dalam proses PdP (Hasan Langgulung, 2003).

Menurut Noornajihan Jaafar \& Ab Halim Tamuri (2013), guru Pendidikan Islam perlu memiliki ciri keperibadian yang tinggi agar tugas mendidik dan membimbing murid berjaya mencapai matlamat seperti yang telah ditetapkan dalam Falsafah Pendidikan Islam. Guru sebagai murabbi menggalas tugas mengajar dan juga memastikan kejayaan murid dalam akademik, sahsiah juga rohani. Berdasarkan pendapat di atas, kepentingan PdP memang tidak dapat dinafikan kerana proses pembelajaran, pembinaan akhlak, penanaman akidah dan pemantapan ilmu dilaksanakan di dalam bilik darjah. Oleh itu kajian ini membincangkan mengenai cara dan amalan bersedekah guru-guru 
Pendidikan Islam prasekolah yang diharapkan memberi impak positif pada pembentukan sahsiah murid-murid.

\subsection{PENGERTIAN SEDEKAH}

Perkataan sedekah berasal dari 'Sadaqa' yang bermaksud benar, iaitu orang yang benar imannya. Hal ini kerana orang yang bersedekah adalah orang yang memiliki sifat benar dan sempurna, perkara yang diberikan kepada fakir kerana Allah SWT.Perkataan"الذي الصدقة يعطي" bemaksud "متصدق" merupakan orang yang member sedekah, dan perkataan"مصدق" pula bermaksud "القبل " "للصدقةmerupakan orang yang menerima sedekah (Ibnu Manzur, 1997). Manakala menurut syarak pula, pengertian sedekah sama dengan maksud infak dari segi hukumnya. Oleh itu, perkataan "صدقة merupakan perkataan yang menjelaskan definisi pemberian atau bantuan yang diberikan oleh manamana pihak secara sukarela atau ikhlas semata-mata kerana Allah SWT (Ruzian Markom, Mohammad Ramzi Zakaria, \& Asma Hakimah Ab Halim, 2015). Menurut Ariffin Omar (2006), terdapat ulama yang menyebut amalan bersedekah dalam kitab mereka antaranya Imam Al-Nawawi (1991) dalam Kitab Minhaj al-Talibin wa Umdah al-Muftin dan Shaikh Al-Ansari (1997) dalam kitabnya AlManhaj. Walau bagaimanapun, mereka tidak membincangkan amalan sedekah ini secara lebih terperinci.

Sadiyah Syekh Bahmid (2014), menyatakan bahawa pengertian sedekah adalah jujur, benar dan memberi dengan ikhlas. Oleh itu, orang yang bersedekahbersikap jujur kepada dirinya dengan kurniaan Allah SWT. Menurut istilah syarak pula, sedekah bermaksud sesuatu yang dikeluarkan atau dilakukan oleh seorang muslim dari harta atau lainnya dengan tujuan untuk mendekatkan diri kepada Allah SWT. Sedekah terbahagi kepada dua kategori, iaitu sedekah wajib, iaitu zakat dan sedekah sunat, iaitu at-tatawwu'. Sheikh Abdullah Muhammad Basmeh (1995) menjelaskan maksud yang sedekah sunat seperti pelbagai jenis derma dan khairat merupakan tanda bersyukur atas segala nikmat kurniaan Allah SWT terutama nikmat 'Islam'.

Kajian ini hanya berkisarkan sedekah sunat. Menurut Mohd Hafiz Mohd Dasar \& Hamdana Abd Hafidz (2015) dana sedekah boleh berbentuk barangan bernilai atau wang. Nilai barangan tersebut tidak terikat dengan nilai yang ditetapkan oleh syarak'. Pemberi bebas menentukan kadar nilai barangan yang diberi. Selain itu, pemberi juga bebas memberi sedekah kepada pihak yang ditentukan oleh pemberi. Oleh itu, sedekah sangat fleksibel dan mudah dilakukan untuk menjadikan amalan soleh setiap Muslim.

\subsection{DALIL SEDEKAH SUNAT}

Tuntutan untuk bersedekah merupakan salah satu daripada syariah Islam. Hal ini berdasarkan firman Alah SWT dalam

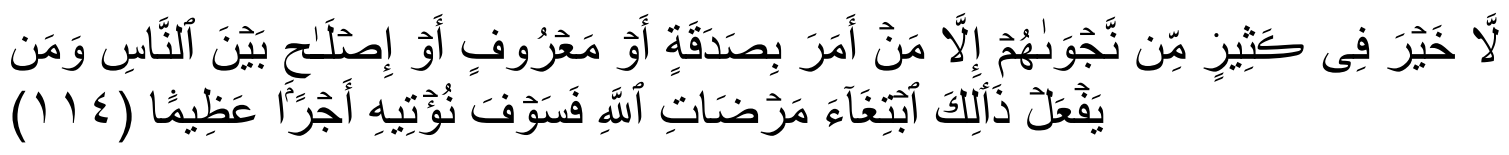

Maksud: Tidak ada kebaikan pada kebanyakan bisikan mereka, kecuali bisikan orang yang menyuruh bersedekah, atau berbuat kebaikan, atau mendamaikan antara manusia. Dan sesiapa yang berbuat demikian dengan maksud mencari keredaan Allah, tentulah Kami akan memberi kepadanya pahala yang amat besar.

(Surah al-Nisa, 4:114)

Ariffin Omar, (2006) menjelaskan mengenai perkataan sedekah menurut al-Quran berdasarkan beberapa ayat yang dikemukakannya adalah mengikut kedudukan ayat berkaitan. Tafsiran perkataan 
sedekah antaranya adalah sedekah wajib, pelupusan hutang, dan sedekah tatawwu', iaitu sedekah sunat.

Selain itu, terdapat banyak hadis Rasulullah SAW berhubung amalan bersedekah. Sebagai contoh satu hadis menjelaskan (Muslim, t.th.: 1006):

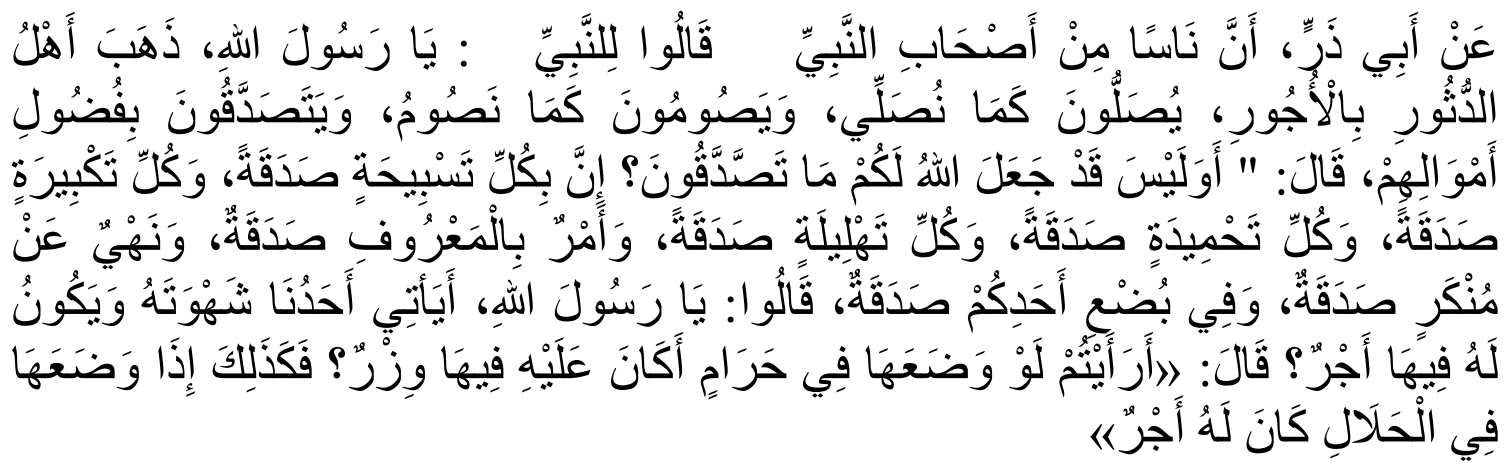

Maksud: Abu Thar RA berkata: "Sesungguhnya sebahagian dari para sahabat rasulullah berkata kepada Nabi Wahai Rasulullah, orang-orang kaya lebih banyak mendapat pahala, mereka mengerjakan solat sebagaimana kami solat, mereka berpuasa sebagaimana kami berpuasa, dan mereka bersedekah dengan kelebihan harta mereka". Nabi SAW bersabda, "bukankah Allahmenjadikan bagi kamu sesuatu untuk bersedekah? Sesungguhnya tiaptiap tahlil adalah sedekah, menyuruh kepada kebaikan adalah sedekah, mencegah kemungkaran adalah sedekah dan persetubuhan salah seorang antara kamu dengan (isterinya) adalah sedekah. Mereka bertanya, "wahai Rasulullah, apakah pahala? Rasulullah menjawab, "tahukah engkau jika seseorang memenuhi syahwatnya pada yang haram, dia berdosa. Demikian pula jika ia memenuhi syahwatnya itu pada yang halal, ia mendapat pahala”.

(H.R Muslim)

Menurut hadis ini, Rasulullah SAW menyatakan bahawa sedekah bukan sahaja berbentuk harta benda tetapi juga berbentuk amalan harian. Rasulullah SAW menyebut bahawa tasbih, tahlil dan tahmid termasuk kategori sedekah. Menyuruh kepada kebaikan dan mencegah kemungkaran juga termasuk sedekah. Begitu juga dengan hubungan suami isteri juga dikira sebagai amalan soleh dan termasuk dalam amalan sedekah (Sadiyah Syekh Bahmid, 2014). Selain hadis ini, terdapat juga hadis lain yang menyatakan amalan sedekah sepertimana berikut (Al-Bukhari, 2001: 1436):

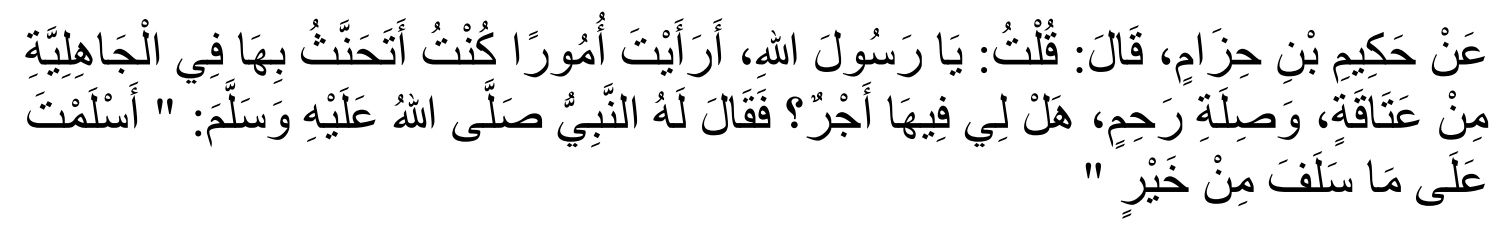

Maksud: Hakim bin Hizam RA berkata:"Akubertanya: "Wahai Rasulullah, apakah jawapan anda terhadap beberap aperkara yang saya lakukan sebagai ibadah semasa jahiliah seperti sedekah, memerdekakan hamba, dan silaturahim? Apakah ada ganjaran pahala padanya? Lalu Nabi SAW bersabda: Anda menganut Islam bersama-sama dengan kebaikan yang silam."

(H.R Al-Bukhari)

Perkataan sedekah dalam nas di atas memberi erti pemberian atau derma (Ruzian Markom et al., 2015). 


\subsection{PERUNTUKAN UNDANG-UNDANG BERKENAAN SEDEKAH}

Menurut Ruzian Markom et al.(2015), sedekah merupakan instrumen yang wujud sejak sebelum zaman Rasulullah SAW lagi. Oleh itu, tiada peruntukan undang-undang atau peraturan keatas pemberi atau penerima sedekah. Begitu juga tiada sebarang peruntukan atau status yang menyentuh intrumen sedekah ini secara umum atau khusus. Walaubagaimanapun terdapat peruntukan lain dalamAkta / Enakmen Pentadbiran Agama Islam Negeri-negeri di Malaysia selain negeri Sarawak yang hanya mengariskan kebenaran untuk kutipan pungutan khairat. Kutipan pungutan khairat ini bermaksud kutipan dari sedekah dan derma dari badan-badan atau individu-individu tertentu. Seksyen 84(1), Akta Pentadbiran Undang-undang Islam (Wilayah-wilayah Persekutuan) 1993 menyatakan bahawa:

"Majlis boleh memungut, atau memberikan surat kebenaran dengan termaterma yang difikirkan patut kepada mana-mana orang atau kumpulan orang, membenarkan orang atau kumpulan orang itu memungut wang atau sumbangan-sumbangan lain bagi apa-apa maksud khairat bagi menyokong dan memajukan agama Islam atau bagi faedah orang-orang Islam mengikut Hukum Syarak.” Berdasarkan akta ini menunjukkan bahawa amalan sedekah juga diperundangkan dalam undang-undang negeri di Malaysia.

\subsection{OBJEKTIF DAN PERSOALAN KAJIAN}

Objektif kajian ini ialah mengenal pasti amalan bersedekah dalam kalangan guru prasekolah ketika P\&P mata pelajaran Pendidikan Islam di dalam kelas. Manakala persoalan kajian pula menyentuh kepada persoalan "Bagaimanakah amalan bersedekah dilaksanakan oleh guru prasekolah ketika PdP Pendidikan Islam di dalam kelas?"

\subsection{METODOLOGI KAJIAN}

Kajian ini menggunakan metode kualitatif dengan reka bentuk kajian kes, iaitu satu kes pelbagai tempat (Merriam, 1998). Dalam kajian ini, pengkaji juga memilih kajian pelbagai kes (Miles \& Huberman, 1994; Yin, 2009). Pelbagai kes merujuk kepada beberapa orang guru yang memberikan data tentang PdP Pendidikan Islam, manakala pelbagai tempat pula merujuk kepada beberapa buah sekolah iaitu dua buah sekolah kebangsaan dan dua buah TABIKA KEMAS yang dijadikan sebagai tempat kajian ini. Pengumpulan data melalui pemerhatian dan temu bual mendalam menjadi tunjang kepada kajian ini. Pengkaji juga menggunakan analisis dokumen sebagai teknik triangulasi data bagi kesahan data. Penggunaan kaedah kajian kes ini membolehkan pengkaji mendapatkan maklumat yang terperinci tentang amalan murni dalam kalangan guru prasekolah yang dikaji(Creswell, 2009), serta memahami fenomena dengan lebih mendalam (Yin, 1994). Seterusnya pengkaji dapat mencungkil emosi, perasaan, dan pemikiran peserta kajian mengenai amalan tersebut. Pengkaji adalah instrumen utama kajian ini bagi memahami tingkah laku serta kata-kata, menggunakan pengalaman dan pengetahuan bagi meneroka meneliti dan tentang apa yang dikaji dengan lebih bermakna (Marohaini Yusoff, 2001). Dalam kajian ini, peserta kajian diberi kod GPSK1, GPSK2, GPSKK1 dan GPSKK2. Manakala prasekolah pula diberi kod PS1, PS2, PS3 dan PS4.

Peserta kajian dipilih berdasarkan teknik sampel bertujuan, iaitu pemilihan bertujuan bagi meningkatkan kredibiliti dapatan kajian (Patton, 1990). Pengkaji memilih peserta kajian berdasarkan prinsip asas dasar prasekolah yang ditetapkan oleh KPM, iaitu semua prasekolah hendaklah menggunakan Kurikulum Standard Prasekolah Kebangsaan.

Seterusnya, guru prasekolah perlu mempunyai latihan dalam bidang pendidikan prasekolah. Setiap prasekolah perlu mempunyai kemudahan fizikal dan peralatan bersesuaian dan berkualiti (Sektor Pengurusan Prasekolah, n.d.). Berdasarkan prinsip KPM dan objektif kajian ini, pengkaji memilih dua orang guru prasekolah yang sedang mengajar di sekolah rendah, melalui maklumat daripada pihak Jabatan Pendidikan Daerah Johor Bahru (JPN) dan Pejabat Pelajaran Daerah Johor 
berdasarkan maklumat dari Pengarah KEMAS Johor Bahru. Kesemua peserta kajian mengajar mata pelajaran Pendidikan Islam di prasekolah tersebut. Keempat-empat guru perempuan ini berpengalaman mengajar prasekolah melebihi tiga tahun dan mendapat kursus khusus untuk bidang pendidikan prasekolah.

Kesahan dan Kepercayaan Data persediaan bagi proses pengutipan data agar data ada kesahan dan kebolehpercayaan. Sebelum menjalankan kajian lapangan, pengkaji mendapatkan kesahan senarai semak pemerhatian daripada penyelia dan tiga orang pakar. Mengenai kesahan protokol temu bual, pengkaji mendapatkan pengesahan dari tujuh orang pakar untuk menilai dan menyemak soalan protokol yang dibina. Pakar yang terpilih terdiri dari pakar pendidikan kanak-kanak, pakar dalam bidang pendidikan serta pakar dalam Pendidikan Islam yang terdiri dari pensyarah universiti tempatan.

Data pemerhatian dan temu bual dilakukan proses transkripsi. Seterusnya pengkaji menganalisis data menggunakan perisian NVivo 11. Sebelum proses analisis dilakukan menggunakan perisian tersebut, semua hasil transkripsi melalui proses semak semula (peer-checking) oleh peserta kajian. Seterusnya pengkaji mencari tema-tema penting dan sub-sub tema melalui penganalisisan tersebut.

\subsection{PERBINCANGAN DAPATAN KAJIAN}

Hasil kajian mendapati guru prasekolah sentiasa menerapkan nilai murni dalam PdP mereka. Perkara ini bertepatan dengan objektif KSPK, iaitu mengamalkan nilai Islam dalam kehidupan seharian (KPM, 2016). Guru kerapkali memberi sesuatu kepada murid. Dalam kajian ini, amalan sedekah guru prasekolah dibahagi kepada tiga bahagian, iaitu bersedekah dengan material, iaitu barang atau benda seperti duit dan pensel, bersedekah dengan bukan material seperti kata-kata yang baik, nasihat, teguran dan sentuhan seperti pelukan. Bahagian ketiga pula ialah bersedekah dengan material dan bukan material seperti menghantar murid ke kem.

Bersedekah dengan material merujuk kepada pemberian yang dilakukan oleh guru kepada murid prasekolah adalah berbentuk barang-barang, duit, dan pensel. Guru prasekolah kerap memberi sedekah kepada murid berupa barangan seperti pensel, duit dan coklat. Petikan temu bual GPSK1 membuktikan Guru pra sekolah memberi sedekah yang berbentuk material iaitu:

\section{"Kalau dekat raya tu bulan puasa tu duit lah biasanya, duit raya lah biasanya."}

(GPSK1 TB)

"Kadang-kadang memang kita kena sediakan walaupun pensel satu macam buat kuiz ke pertandingan siapa boleh jawab."

"Siapa hafal lima-lima lafaz niat, dapat RM5."

(GPSK1 TB)

(GPSK2TB)

Begitu juga dengan GPSKK2 dari PS4 juga kerap memberi murid hadiah untuk menarik perhatian murid. Beliau menyatakan,

"bagi hadiah saja je nak tarik perhatian kan, kena sediakan lah hadiah, hadiah bukan apa pun cokie-cokie ke...apa tu je, suka.."

(GPSKK2 TB)

Sedekah guru ini boleh merangsang murid untuk terus belajar serta memberi keseronokan kepada mereka. Sebagaimana pendapat Haliza Hamzah \& Samuel (2014), guru perlu menunjukkan tingkahlaku yang baik agar dteladani oleh murid. Kamarul Azmi Jasmi \& Ab. Halim Tamuri (2007)menegaskan peri pentingnya guru kreatif dalam mempelbagaikan teknik PdP antaranya 
Guru juga mengorbankan kewangan mereka sendiri untuk membantu murid. Contohnya seperti GPSKK1 dari PS3 yang sanggup membantu membayarkan yuran muridnya agar bebanan masalah ibubapa murid tersebut tidak menghalang pembelajaran anak mereka. GPSKK1 menyatakan

"Macam-macam kisah bergaduh dekat sekolah, dia tak macam sekolah tau sebab kita tadika ni dia lebih pada tak formal sangat, inilah satu institusi, tadika KEMAS Idaman, yang bergaduh depan-depan ni, dia kata ada masalah keluarga, "tak apa lah puan masalah duit tak payah lah bayar, puan datang je hantar anak puan, tak apa lah" yang lain tu tak apa lah, saya kira sedekah je lah, "tak apa ke umi, malu lah saya."

(GPSKK1 TB)

Manakala bersedekah bukan material pula merujuk kepada memberi khidmat bantuan kepada murid serta memberi motivasi dan galakan untuk berbuat baik. Pengkaji melihat perlaksanaan amalan sedekah bukan material ini ketika pemerhatian semasa proses $\mathrm{P} \& \mathrm{P}$, antaranya guru mengasah pensel murid. Hal ini dibuktikan melalui petikan temu bual berikut:

"Guru mengasahkan pensel warna dan melihat-lihat kerja murid.”

(GPSKK1 PM)

Dari aspek kata-kata yang baik pula seperti kata-kata seorang ibu kepada anaknya, contohnya kata-kata GPSK2 dari PS2 seperti berikut:

"Siapa budak baik dia..., budak baik Allah sayang kan, kalau Allah sayang masuk syurga."

(GPSK2 PM)

"Tengok sini, duduk elok-elok, budak yang Allah sayang, tengok sini duduk elokelok nanti Allah sayang masuk mana? Syurga."

(GPSK2 PM)

Seterusnya, kata-kata GPSK1 dari PS1:

"Tangan kanan sayang, tangan makan nasi, mana tangan kanan, Okey tangan kanan di atas tangan kiri, gini.”

(GPSK PM)

"GPSKK1 ke belakang kelas dan murid memusing kerusi ke belakang. "Pandang sini semua sayang, Umi nak pinjam mata sekejap, mata, mana mata? Ni jawab murid, ha kata GPSKK1"

(GPSKK1 PM)

Bersedekah dengan material dan bukan material bermaksud bersedekah dengan kedua-duanya seperti tenaga dan kewangan seperti yang dinyatakan oleh GPSK1 semasa sesi temu bual:

"Hari Khamis ni sepatutnya ajar ni tapi guru besar dah amanahkan hantar budak ke Kem Bestari Solat dekat Star hill”,

(GPSK1 TB) 
"Haa..kita dari segi kelas pun gitu lah kita kena ni lah sebab bahagian kita kan Pendidikan Islam bahagian kita kalau dia orang bagi satu tempat tu untuk Pendidikan Islam, maksudnya kita lah yang uruskan"

(GPSK1 TB)

"Kita orang cari sendiri"

(GPSK2 TB)

"Buat sendiri kertas A4 warna laminate je"

(GPSK2 TB)

"Dia kebanyakannya kalau tabika KEMAS ni Puan, kebanyakannya kita sendiri lah dia biasanya yang dibekalkan jabatan tak ada."

(GPSKK1 TB)

"BBM semua kena buat sendiri, tak ada dia orang bagi"

(GPSKK2 TB)

Berdasarkan petikan temu bual di atas, jelas menggambarkan tugas guru di prasekolah tidak hanya terikat dengan sesi PdP semata-mata. Menurut responden, mereka turut dipertanggungjawabkan untuk menguruskan segala hal dan aktiviti luar yang melibatkan pelajar, serta mengeluarkan kos sendiri untuk menceriakan kelas dan kawasan persekitaran sekolah.

Berdasarkan data guru prasekolah juga, bersedekah bertujuan untuk membantu murid dan keluarganya yang bermasalah. Guru juga bersedekah dengan memberi hadiah untuk menarik perhatian agar mereka lebih minat untuk menuntut ilmu. Hal ini kerana, guru sedia maklum bahawa setiap amal kebaikan yang dilakukan pasti akan dibalas oleh Allah SWT. Bertepatan dengan firman Allah SWT:

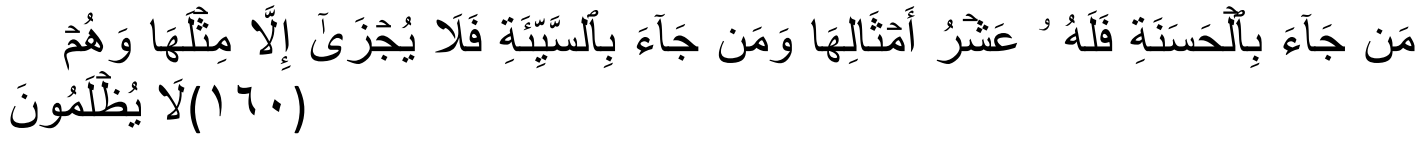

Maksud: Barang siapa melakukan kebaikan mendapat balasan sepuluh kali ganda amalannya. Dan barang siapa melakukan kejahatan dibalas seimbang dengan kejahatannya. Mereka sedikit pun tidak dirugikan dizalimi."

(Surah al-An'am, 6:160)

Ayat di atas jelas menunjukkan bahawa, Allah SWT menyatakan bahawa tidak akan rugi bagi orang-orang yang bersedekah. Hal ini kerana, walaupun nilaian yang dikeluarkan itu hanya kecil, namun Allah SWT akan pasti akan membalas sebanyak sepuluh kali ganda.

Selain itu, sifat bersedekah dalam kalangan guru prasekolah ini secara tidak langsung dapat memberi contoh yang baik kepada pelajar. Hal ini kerana, walaupun para pelajar masih kecil namun, mereka pada hakikatnya memerhatikan segala tindak tanduk dan kelakuan orang dewasa. Justeru, guru di prasekolah perlu berakhlak dengan akhlak yang mulia kerana sikap dan kelakuan mereka akan ditiru oleh pelajar yang masih kecil. Sejajar dengan sebuah hadis Rasulullah saw yang diriwayatkan oleh Abu Hurayrah RA yang bermaksud (Al-Bukhari, 2001: 1385; Muslim, t.th.: 2658):

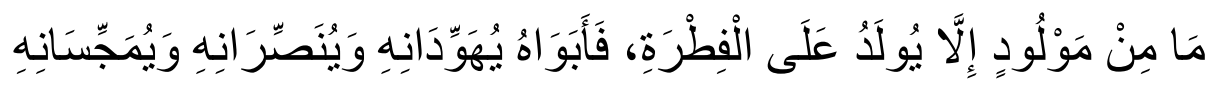


Maksud: Seorang bayi tidak dilahirkan ke dunia ini melainkan ia berada dalam kesucian (fitrah). Kemudian kedua ibu bapanya lah yang akan membuatnya menjadi Yahudi, Nasrani, mahupun Majusi"

(Al-Bukhari dan Muslim)

Sikap baik yang ditonjolkan oleh guru seperti amalan memberi ini dapat dipupuk dalam diri pelajar. Keadaan ini juga menjadikan guru sebagai qudwah hasanah atau role-model kepada para pelajar di sekolah (Habibah@Artini Ramli \& Zaharah Hussin, 2014; Kamarul Azmi Jasmi \& Ab. Halim Tamuri, 2007; Kamarul Azmi Jasmi, Ab Halim Tamuri, \& Mohd Izham Mohd Hamzah, 2012; Muhammad Nurfahmi Mohamed Yusof, Rohana Hamzah, \& Amirmudin Udin, 2010). Oleh yang demikian, guru perlu berhati-hati dalam setiap perbuatan, percakapan, pergaulan, berpakaian, serta adab makan dan minum. Hal ini kerana, setiap aspek tersebut akan di perhati dan ditiru oleh para pelajar mereka.

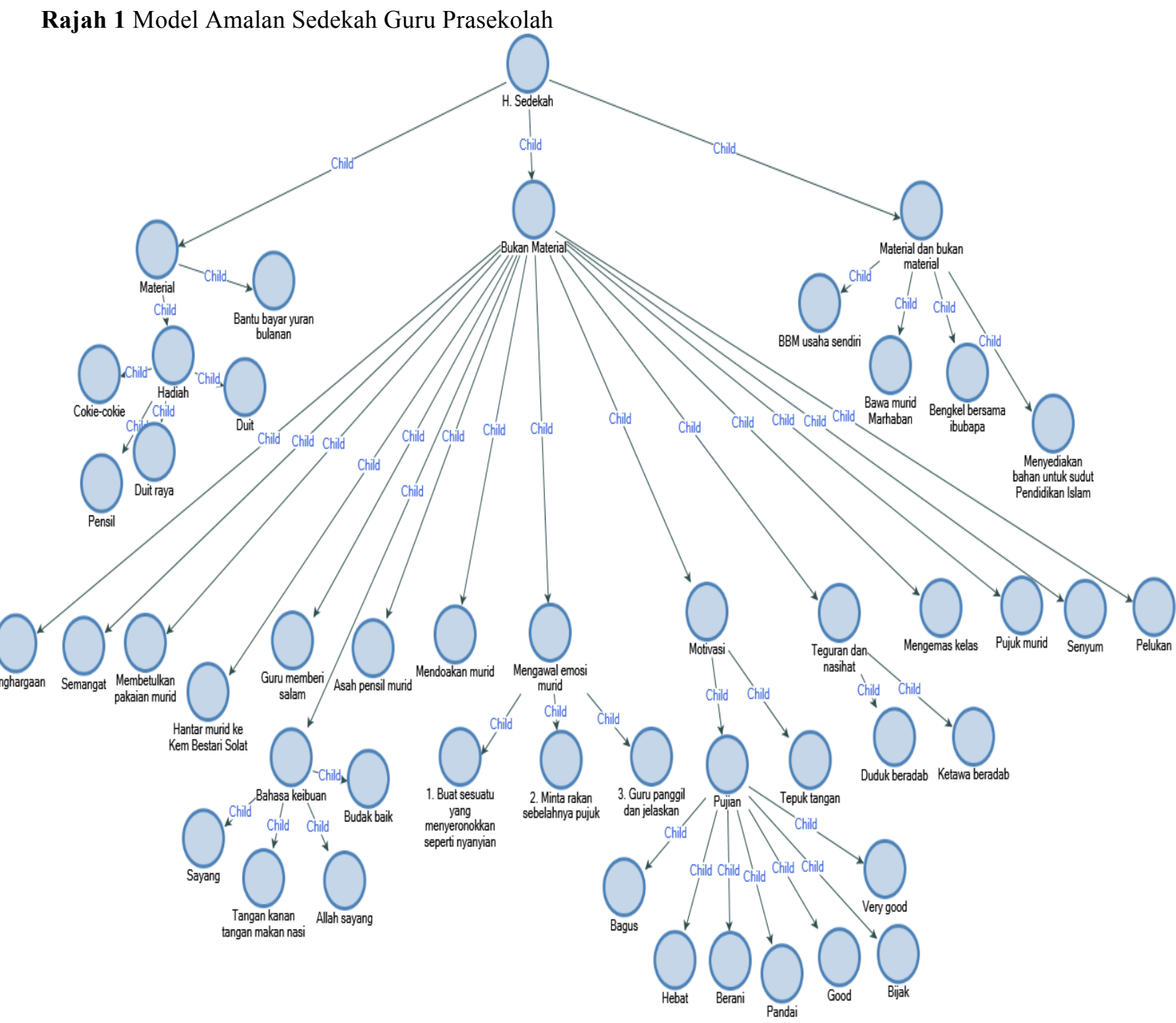

\subsection{KESIMPULAN}

Berdasarkan dapatan menjelaskan bahawa penerapan nilai murni khususnya amalan sedekah sunat sentiasa berlaku semasa dan di luar P\&P. Amalan bersedekah yang diamalkan oleh guru menunjukkan hubungan kasih sayang antara guru dengan muridnya. Hubungan guru-murid seperti ibu dan anak bertepatan dengan sirah Rasulullah SAW yang dibincangkan oleh Abdul Muhsien Sulaiman (2014) menganggap sahabatnya seperti kawan atas hubungan kasih sayang, bukan seorang guru dan 


\section{RUJUKAN}

Abdul Muhsien Sulaiman. (2014). Peranan Guru Pendidikan Islam dalam Pembetukan Akhlak Murid dari Aspek Hubungan Guru-Murid Berasaskan Abu Talib Al-Makki (w.386H/996M). Tesis PhD, Institut Pengajian Siswazah, Universiti Malaya.

Al-Ansari, Zakariya Ahmad. 1997. Manhaj al-Tullab fi Fiqh al-Imam al-Shafi'i RA. Silah Muhammad 'Uwaydah (Ed.). Beirut: Dar al-Kutub al-'Ilmiyyah.

Al-Bukhari, Abu Abdullah Muhammad. 2001. Al-Jami ‘ al-Musnad al-Sahih al-Mukhtasar min Umur Rasulullah SAW wa Sunanihi wa Ayyamihi-Sahih al-Bukhari. Muhammad Zuhair Nasir Al-Nasir (Ed.). Jld. 1-9. Masurah: Dar Tuq al-Najat.

Al-Bukhari, A. A. M. (1994). Sahih al-Bukhari (Vol. 1-5). Beirut: Dar al-Fikr.

Al-Nawawi, M. al-D. A. Z. Y. (1981). Sahih Muslim bi sharh al-Nawawi (Vol. 1-18). Beirut: Dar al-Fikr.

Al-Nawawi, Mahyuddin. 1991. Rawdat al-Talibin wa Umdat al-Muftin. Zuhair al-Shawish (Ed.). Jld. 1-12. Beirut: Al-Maktab al-Islami.

Ariffin Omar. (2006). Sedekah Jaminan Keharmonian Umat Menurut Sunah. Kuala Lumpur: Utusan Publications \& Distributors Sdn. Bhd.

Creswell, J. W. (2009). Research design: Qualitative, quantitative, and mixed methods approaches. Research Design qualitative quantitative and mixed methods approaches (3rd ed.). California: Saga Publications, Inc.

Habibah@Artini Ramli, \& Zaharah Hussin. (2014). Profesionalisme Perguruan Pendidikan Islam Berasaskan Riadhah Ruhiyyah : Satu Analisa. The Online Journal of Islamic Education, 2(1), 7-24.

Haliza Hamzah, \& Samuel, J. N. (2014). Pengurusan Bilik Darjah dan Tingkah Laku. Selangor: Oxford Fajar Sdn.Bhd.

Ibnu Manzur. (1997). Lisan al-Arab. Beirut: Dar Ihya' al-Turath al-'Arabiyy.

Kamarul Azmi Jasmi, \& Ab. Halim Tamuri. (2007). Pendidikan Islam : Kaedah pengajaran dan pembelajaran. Skudai: Universiti Teknologi Malaysia.

Kamarul Azmi Jasmi, Ab Halim Tamuri, \& Mohd Izham Mohd Hamzah. (2012). Sifat dan Peranan Keperibadian Guru Cemerlang Pendidikan Islam (GCPI) dan Hubungannya Dengan Motivasi Pelajar. Jurnal Teknologi, 51, 57-71.

KPM. (2016). Pendidikan Prasekolah Dokumen Standard Kurikulum dan Pentaksiran DSKP $K S P K$.

Marohaini Yusoff. (2001). Pertimbangan Kritikal dalam Pelaksanaan Kajian Kes Secara Kualitatif Marohaini Yusoff. In M. Yusoff (Ed.), Penyelidikan Kualitatif Pengalaman Kerja Lapangan Kajian (pp. 35-60). Kuala Lumpur: Penerbit Universiti Malaya.

Merriam, S. B. (1998). Qualitative Research and Case Study Applications in Education. San Francisco: John Wiley \& Sons, Inc.

Miles, M. B., \& Huberman, A. M. (1994). Qualitative Data Analysis (Second Edi). California: Sage Publications. 
Mohd Hafiz Mohd Dasar, \& Hamdana Abd Hafidz. (2015). Pelaburan Dana Sedekah Menurut Perspektif Syariah: Satu Tinjauan. In International Conference on Islamic Jurisprudence 2015 (Vol. 53, pp. 276-286).

Muhammad Nurfahmi Mohamed Yusof, Rohana Hamzah, \& Amirmudin Udin. (2010). Kemantapan Penghayatan Guru Terhadap Falsafah Pendidikan Kebangsaan Asas Membangunkan Guru Cemerlang. Journal of Edupress, 1(September), 271-278. Retrieved from http://eprints.utm.my/14921/

Muslim, Abu al-Husayn. t.th. Sahih Muslim. Jld. 1-8. Beirut: Dar al-Fikr.

Patton, M. (1990). Qualitative Evaluation and Research Methods. Beverly Hills, CA:Sage.

Ruzian Markom, Mohammad Ramzi Zakaria, \& Asma Hakimah Ab Halim. (2015). Kerangka Perundangan Rumah Sedekah sebagai Institusi Perbankan: Satu Tinjauan Awal. In 1st Seminar on Sadaqa House 2015 (pp. 23-31).

Sadiyah Syekh Bahmid. (2014). Sedekah dalam Pandangan al-Quran. Rausyan Fikr, 10.

Sektor Pengurusan Prasekolah, B. P. S. H. (n.d.). Prasekolah. Retrieved from http://www.moe.gov.my/v/prasekolah

Sheikh Abdullah Muhammad Basmeh. (1995). Mastika Hadis Rasulullah SAW (Jilid Keti). Kuala Lumpur: Jabatan Perdana Menteri.

Yin, R. K. (1994). Case Study Research Design and Methods Fourth Edition (4 td ed.). California: SAGE Publication, Inc.

Yin, R. K. (2009). Case Study Research Design and Methods Fourth Edition. United States of America: Sage Publications. 